\title{
Obtaining Stable Binary Fuel Systems
}

\author{
Vasily I. Murkoa, \\ Vladimir A. Kulagin*b and Marina P. Baranova ${ }^{b}$ \\ aSPE "Sibecotechnika", CJSC \\ 2 Kommunarov, Novokuznetsk, 654079, Russia \\ ${ }^{b}$ Siberian Federal University \\ 79 Svobodny, Krasnoyarsk, 660041, Russia
}

Received 24.03.2017, received in revised form 04.08.2017, accepted 21.10.2017

The stable fuel coal-water slurry producing processes regularities from varying degrees of metamorphism coal and coal sludge were educed for its industrial use. The CWS stabilization and rheological characteristics produced using SAS (surface-active substance) were investigated. The observed regularities demonstrate the ability to optimize the slurry properties in industrial conditions by joint change of the additive amount and the physical and chemical coal composition regulation.

Keywords: coal water fuel, stable, coal sludge.

Citation: Murko V.I., Kulagin V.A., Baranova M.P. Obtaining stable binary fuel systems, J. Sib. Fed. Univ. Eng. technol., 2017, 10(8), 985-992. DOI: 10.17516/1999-494X-2017-10-8-985-992.

\section{Получение стабильных бинарных топливных систем}

\author{
В.И. Мурко ${ }^{a}$ В.А. Кулагин ${ }^{\sigma}$ М.П. Баранова \\ 'ЗАО НПП «Сибэкотехника» \\ Россия, 654079, Новокузнеик, пр-д Коммунаров, 2 \\ ${ }^{6}$ Сибирский федеральный университет \\ Россия, 660041, Красноярск, пр. Свободный, 79
}

\begin{abstract}
Установлена зависимость стабильности получаемых водоугольных суспензий от степени метаморфизма угля и технических характеристик угольных шламов для их промышленного использования. Исследованы стабилизачионные и реологические характеристики ВУС, полученных с применением пластифицирующих агентов. Обнаруженные закономерности дают возможность управлять параметрами суспензий в промышленных условиях совместным изменением количества добавки и регулированием физико-химического состава угля.
\end{abstract}

Ключевые слова: водоугольное топливо, стабильность, угольные шламы.

(C) Siberian Federal University. All rights reserved

* Corresponding author E-mail address: v.a.kulagin@mail.ru 


\section{Введение}

Технологии производства, транспортировки и прямого сжигания водоугольных суспензий (ВУС) без обезвоживания и сушки угля - актуальное и современное направление развития теплоэнергетики. Возможность использования в процессе получения ВУС некондиционных углей и отходов угледобычи и углепереработки позволяет решать вопросы ресурсосбережения. Горючей основой суспензионного топлива могут быть неэнергетические бурые угли, твердые остаточные продукты переработки угля и нефти и мн. др. Эти отходы представляют экологическую опасность, а их хранение требует значительных затрат $[1,2]$.

В ходе активной механохимической деструкции угольных частиц в водной фазе образуется бинарная система. Эта система называется суспензией, но несущей средой являются коллоидные растворы наночастиц в жидком растворителе [3, 4]. Вследствие малых размеров включений такие системы обладают особыми физико-химическими свойствами. Системы имеют повышенную поверхностную энергию в связи с большим количеством атомов, находящихся в возбуждённом состоянии и имеющих не менее одного свободного электрона на внешнем энергетическом уровне. Такие системы вполне могут быть отнесены к нанодисперсиям. Из-за своего строения и нестабильности размеров агрегатов наночастиц нанодисперсии, как правило, довольно нестабильны. Их свойства легко меняются и зависят от внешнего воздействия [5]. Основная задача, которая должна быть решена на пути их промышленного использования, получение устойчивых нанодисперсий с воспроизводимыми свойствами.

Таким образом, технологические и теплотехнические характеристики топливных водоугольных суспензий, предназначенных для прямого сжигания, в значительной степени определяются степенью измельчения и физико-химическим составом используемых углей. Цель данной работы состояла в развитии теоретических основ для технологических решений получения и применения ВУС.

\section{Экспериментальное исследование и обсуждение результатов}

Коллоиды широко распространены в структуре минеральных веществ земной поверхности (глины, силикагели, органогели и др.) и в достаточно большом количестве имеются в углях. Минеральные примеси, содержащиеся в твердой фазе, способствуют образованию коагуляционных структур в ВУС, тем самым влияя на реологические свойства и седиментационную устойчивость. Кроме того, длительное контактирование этих примесей с водой может влиять на реологические характеристики ВУС.

В ходе работы был проведен ряд экспериментов для исследования влияния количества минеральных примесей на вязкость и стабильность суспензий. Для этого использовались бурые угли марки «Б2» с зольностью от 10,6 до 34,7 \%. Из каждой пробы угля с определенной зольностью были получены серии суспензий с различной массовой долей твердой фазы. Содержание твердой фазы этих суспензий без применения пластифицирующих добавок составило, в зависимости от зольности, в среднем 43 \%. Низшая теплота сгорания ВУС в этом случае 5,61-7,66 МДж/кг.

Для увеличения содержания твердой фазы в ВУС был исследован ряд пластифицирующих добавок, имеющих щелочную среду. Разжижающий механизм действия щелочи на водоугольную систему можно объяснить образованием натриевых солей гуминовых кислот, которые

$$
\text { - } 986 \text { - }
$$


обладают пластифицирующим и стабилизирующим действием. Кроме того, введение щелочи на стадии мокрого помола угля вызывает к интенсификацию процессов механохимической деструкции по связям $\mathrm{C}-\mathrm{O}-, \mathrm{C}-\mathrm{C}-$ и $\mathrm{C}-\mathrm{H}$ и разрушение исходной структуры органических веществ угля. Наиболее высокие содержания твердой фазы в ВУС с добавкой $\mathrm{NaOH}$ (47 \%) получены при использовании высокозольных углей с $A^{d}=31-34,7$ \%. Однако теплота сгорания таких суспензий за счет высокого содержания минеральной составляющей ниже, чем у низкоконцентрированных ВУС с $C_{\text {тв }}=43-45 \%$, полученных из углей с зольностью 20,4-26,3 \%.

Реологические кривые, представленные на рис. 1, показывают, что ВУС из бурого угля характеризуются псевдопластическим типом течения.

В ходе работы также была исследована стабильность ВУС из бурого угля как в статических, так и в динамических условиях. Приготовленные водоугольные суспензии хранились при постоянной температуре в стеклянных емкостях объемом 500-1000 мл. Общее время хранения суспензии в статических условиях составляло 60 сут. Седиментационную устойчивость ВУС исследовали на $5,10,15,30,45$ и 60 -й день после приготовления по наличию осадка и водоотделения. Для количественной оценки стабильности ВУС проводили исследования седиментационной устойчивости суспензий как с пластифицирущими добавками, так и без них.

Вязкотекучие характеристики суспензий, зольность которых составляла 20,4-27,4 \%, практически не повысились после хранения. Это указывает на отсутствие в минеральной части угля данной зольности набухающих в водной среде глинистых минералов. Соотношение оксидов $\mathrm{SiO}_{2} / \mathrm{Al}_{2} \mathrm{O}_{3}$ в золе этих углей свидетельствует о присутствии глинистых примесей группы каолинита, который относится к неразбухающим минералам и является лиофильным коллоидом.

ВУС с комплексной добавкой на основе щелочи и лигносульфонатов не расслаивались, однако вязкость $\left(\mu_{\text {эф}}\right)$ и напряжение сдвига $\left(\tau_{0}\right)$ через 60 сут увеличилась примерно в 1,5-2 раза.

Проверку водоугольной суспензии на динамическую стабильность проводили на лабораторной качалке, с помощью которой можно моделировать ускорения, превышающие обычную силу тяжести и которые могут иметь место при транспортировании. Динамическая седимен-



Рис. 1. Реограмма течения ВУС ( $\left.A^{d}=19 \%\right)$

Fig. 1. WCS flow rheogram $\left(A^{d}=19 \%\right)$

$$
-987-
$$


тационная устойчивость ВУС оценивалась на вискозиметре «Реотест-2» по методике, разработанной сотрудниками ИФХ РАН. Образцы суспензий подвергались воздействию сдвига по высоте зазора между двумя коаксиальными цилиндрами, один из которых вращается с угловой скоростью, обеспечивающей скорость сдвига суспензии $10 \mathrm{c}^{-1}$. Время вращения цилиндра 60 мин. После этого визуально оценивалось наличие осадка в нижней части цилиндра. Кроме того, в течение часа контролировалось значение вязкости исследуемой суспензии, которая на протяжении всего времени испытаний оставалась без изменений.

Исследования динамической стабильности показали наличие связи седиментационной устойчивости концентрированных водоугольных суспензий с прочностью их структуры, а изменение устойчивости суспензий при применении пластифицирующих добавок связано в первую очередь с влиянием добавок на реологические свойства суспензий.

Определение динамической стабильности ВУС из малозольных углей показало, что расслоение суспензии началось через 17 ч. После первых суток динамических испытаний суспензий на дне колбы произошло выпадение плотного осадка. С увеличением зольности от 12 до 31 и более процентов динамическая стабильность возрастает до 30 и более сут.

Наиболее динамически стабильными были суспензии с комплексными добавками $(\mathrm{NaOH}+$ ЛСТ), их динамическая стабильность превышала 60 сут.

В ходе работы была разработана система размола угля с получением бимодального состава шихты с добавлением бурого угля. В лабораторных условиях изучено влияние на режим приготовления ВУС следующих факторов: соотношения каменного и бурого угля в шихте (КУ:БУ), гранулометрического состава, гомогенизации, содержания пластификатора.

Для экспериментов по приготовлению суспензий использовалась шихта с содержанием бурого угля от 5 до 50 \%. Опыты проводили с каменным углем марки «Д» Кузнецкого бассейна и бурым углем марки «Б2» Березовского месторождения Канско-Ачинского угольного бассейна. Физико-химические характеристики используемых в работе углей и химический состав их золы отражены соответственно в табл. 1 и 2.

Таблица 1. Физико-химические характеристики углей

Table 1. Physical and chemical characteristics of coals

\begin{tabular}{|l|c|c|c|c|c|c|c|c|c|c|c|}
\hline Марка угля & $W_{t}^{r}$ & $W^{r u}$ & $A^{d}$ & $V^{\text {daf }}$ & $\mathrm{C}^{d}{ }_{0}$ & $\mathrm{H}^{\text {daf }}{ }_{0}$ & $\mathrm{~S}^{\text {daf }}{ }_{t}$ & $\mathrm{~N}^{\text {daf }}$ & $\mathrm{O}^{\text {daf }}{ }_{0}$ & $(\mathrm{HA})^{d a f}{ }_{t}$ & $Q_{s}{ }_{s}$ af, МДж/кГ \\
\hline Д & 9,1 & 7,7 & 19,8 & 42,9 & 79,2 & 5,3 & 0,28 & 0,95 & 14,3 & - & 31,5 \\
\hline Б2 & 17,7 & 15,6 & 4,9 & 49,8 & 72,2 & 4,7 & 0,24 & 0,86 & 22,0 & 34,8 & 27,8 \\
\hline
\end{tabular}

Таблица 2. Элементный состав золы

Table 2. Elemental composition of ash

\begin{tabular}{|l|c|c|c|c|c|c|c|c|c|}
\hline Марка угля & $\mathrm{SiO}_{2}$ & $\mathrm{Al}_{2} \mathrm{O}_{3}$ & $\mathrm{Fe}_{2} \mathrm{O}_{3}$ & $\mathrm{TiO}_{2}$ & $\mathrm{CaO}$ & $\mathrm{MgO}$ & $\mathrm{SO}_{3}$ & $\mathrm{~K}_{2} \mathrm{O}$ & $\mathrm{Na}_{2} \mathrm{O}$ \\
\hline Д & 60,8 & 19,4 & 5,2 & 0,7 & 5,5 & 1,8 & 0,7 & 2,7 & 0,6 \\
\hline Б2 & 13,0 & 9,6 & 3,6 & 0,7 & 53,4 & 6,4 & 10,2 & 0,1 & 0,7 \\
\hline
\end{tabular}


Влияние первых трех факторов на процесс приготовления ВУС устанавливали при содержании пластификатора 1 \%. В качестве пластифицирующей добавки использовали реагент $C-3$ (продукт конденсации сульфированного нафталина и формальдегида).

Опыты по приготовлению суспензий проводили в лабораторной цильпебсной мельнице. Приготовление ВУС из смеси углей осуществляли в режиме одностадийного помола при одновременной загрузке угля, воды и пластификатора. Перед загрузкой в мельницу уголь измельчали до класса 0-3 мм и шихтовали в необходимой пропорции. Гомогенизацию осуществляли в мешалке МР-25 при скорости вращения вала 800 об/мин в течение 15 мин. Время помола определяли экспериментальным путем и подбирали таким образом, чтобы получить бимодальное распределение частиц и реологические параметры суспензий, обеспечивающие стабильность и текучесть ВУС. Помол в мельнице в течение 40-50 мин с выходом фракции 0-50 мкм 60-65 \% обеспечивал требуемые характеристики суспензий.

Полученные реологические характеристики суспензий показали, что наиболее приемлемые характеристики ВУС можно иметь при добавке бурого угля в пределах 5-20\%, при этом составе шихты содержание твердой фазы в ВУС снижается в среднем на 1-3\% в сравнении с суспензией из каменного угля. Дальнейшее повышение добавки угля низкой стадии метаморфизма приводит к ухудшению качественных характеристик суспензии. Данные измерений реологических характеристик ВУС после хранения в статических условиях представлены в табл. 3.

Данные таблицы показывают, что после хранения в течение 37 сут наблюдается увеличение вязкости и предела текучести. Следует отметить, что в суспензиях с меньшим содержанием бурого угля реологические параметры увеличивались в большей степени.

Это можно связать со снижением зольности шихты с 19 до 15 \% и уменьшением содержания склонных к набуханию в воде глинистых веществ, которыми в основном была представлена минеральная часть кузнецких углей.

После гомогенизации происходило снижение реологических характеристик суспензий (табл. 4). Причем менялись характеристики в основном за счет снижения консистенции, которую характеризует коэффициент $K$, изменяющийся в $1,2-1,7$ раза.

Исследование седиментационной устойчивости гомогенизированных суспензий показало, что незначительное расслоение наблюдалось у суспензий из всех составов шихты. ВУС с содер-

Таблица 3. Характеристики ВУС после хранения

Table 3. WCS characteristics after storage

\begin{tabular}{|c|c|c|c|c|c|c|c|c|c|c|c|}
\hline \multirow{2}{*}{$\begin{array}{c}\text { № } \\
\text { пробы }\end{array}$} & \multirow{2}{*}{$\begin{array}{c}\text { Соотношение } \\
\text { КУ:БУ }\end{array}$} & \multirow[b]{2}{*}{$A^{d}, \%$} & \multirow{2}{*}{$\begin{array}{c}\text { Длитель- } \\
\text { ность } \\
\text { хранения, } \\
\text { сут }\end{array}$} & \multicolumn{4}{|c|}{ После получения } & \multicolumn{4}{|c|}{ После хранения } \\
\hline & & & & $C_{\mathrm{TB}}, \%$ & $\begin{array}{c}\mu_{\mathrm{c},} \\
\text { Па·c }\end{array}$ & $\tau_{0}$, Па & $\begin{array}{l}\mu_{\text {эфф. }} \\
\text { Па } \mathrm{c}\end{array}$ & $C_{\mathrm{TB}}, \%$ & $\begin{array}{c}\mu_{\mathrm{c},} \\
\text { Па·c }\end{array}$ & $\tau_{0}, \Pi \mathrm{a}$ & $\begin{array}{l}\mu_{\text {эфф, }} \\
\text { Па c }\end{array}$ \\
\hline 4 & $70: 30$ & 15,3 & 34 & 54,5 & 0,64 & 29,5 & 3,72 & 55,0 & 0,84 & 33,0 & 4,25 \\
\hline 5 & $80: 20$ & 16,7 & 30 & 56,5 & 0,65 & 11,0 & 1,83 & 57,3 & 0,94 & 19,0 & 2,79 \\
\hline 6 & $80: 20$ & 16,7 & 30 & 54,5 & 0,47 & 7,0 & 1,30 & 55,4 & 0,67 & 12,0 & 2,01 \\
\hline 9 & $90: 10$ & 18,2 & 37 & 56,4 & 0,56 & 6,0 & 1,21 & 56,7 & 0,62 & 13,0 & 2,11 \\
\hline
\end{tabular}


Таблица 4. Влияние гомогенизации на свойства ВУС

Table 4. Effect of homogenization on the properties of the WCS

\begin{tabular}{|c|c|c|c|c|c|c|c|c|c|c|c|c|c|}
\hline \multirow{2}{*}{$\begin{array}{c}\text { № } \\
\text { пробы }\end{array}$} & \multirow{2}{*}{$\begin{array}{c}\text { Соотношение } \\
\text { КУ:БУ }\end{array}$} & \multirow[b]{2}{*}{$C_{\mathrm{TB}}, \%$} & \multirow[b]{2}{*}{$R_{50}, \%$} & \multicolumn{5}{|c|}{ После получения } & \multicolumn{5}{|c|}{ После гомогенизации } \\
\hline & & & & $\begin{array}{c} \\
\Pi a \cdot c^{n}\end{array}$ & $n$ & $\begin{array}{c}\mu_{\mathrm{c}}, \\
\text { Па·c }\end{array}$ & $\begin{array}{c}\tau_{0}, \\
\Pi a\end{array}$ & $\begin{array}{l}\mu_{\text {эф }} \\
\text { Па·c }\end{array}$ & $\begin{array}{c}K, \\
\Pi a \cdot c^{n}\end{array}$ & $n$ & $\begin{array}{c}\mu_{\mathrm{c}} \\
\prod^{2} \cdot \mathrm{c}\end{array}$ & $\begin{array}{l}\tau_{0} \\
\text { Па }\end{array}$ & $\begin{array}{l}\mu_{э ф}, \\
\prod a \cdot c\end{array}$ \\
\hline 4 & $70: 30$ & 54,5 & 34,1 & 11,8 & 0,4 & 0,6 & 29,5 & 3,7 & 9,5 & 0,4 & 0,6 & 19,0 & 3,1 \\
\hline 5 & $80: 20$ & 56,5 & 37,1 & 3,9 & 0,6 & 0,7 & 11,0 & 1,8 & 2,6 & 0,7 & 0,6 & 9,0 & 1,6 \\
\hline 6 & $80: 20$ & 54,5 & 37,2 & 3,1 & 0,6 & 0,5 & 7,0 & 1,3 & 1,8 & 0,7 & 0,4 & 6,0 & 1,1 \\
\hline 9 & $90: 10$ & 56,4 & 34,2 & 3,2 & 0,6 & 0,6 & 6,0 & 1,2 & 2,3 & 0,7 & 0,5 & 5,0 & 1,1 \\
\hline
\end{tabular}

Таблица 5. Физико-химические характеристики шламов

Table 5. Physical and chemical characteristics of sludges

\begin{tabular}{|c|c|c|c|c|c|c|c|c|}
\hline \multicolumn{10}{|c|}{ Содержание, \%* } \\
\hline$W^{r u}$ & $A^{d}$ & $V^{\text {daf }}$ & $\mathrm{C}^{\text {daf }}$ & $\mathrm{S}^{d}$ & $\mathrm{~N}^{\text {daf }}$ & $\mathrm{O}^{\text {daf }}$ & $\mathrm{H}^{\text {daf }}$ & $Q_{t}{ }^{\text {daf }}, \mathrm{\kappa}$ Дж/кг \\
\hline 5,5 & 20,0 & 39,8 & 76,4 & 0,6 & 2,4 & 16,3 & 4,9 & 31220 \\
\hline
\end{tabular}

* $W^{r}$ u- влаги гигроскопической; $A^{d}-$ зольности; $\mathrm{S}^{\mathrm{d}}-$ серы; $V^{\mathrm{daf}}-$ летучих; $\mathrm{C}^{d a f}-$ углерода; $\mathrm{H}^{d a f}-$ водорода; $\mathrm{O}^{d a f}$ - кислорода; $\mathrm{N}^{d a f}-$ азота.

жанием бурого угля от 5 до 30 \% характеризовалась осадком с рыхлой подвижной структурой в течение всего срока хранения. При содержании бурого угля $~ 50 \%$ осадки были подвижны в первые 7 суток, а затем происходило их уплотнение. Осадки негомогенизированных ВУС были менее подвижны.

Влияние процентного содержания пластификатора $C-3$ изучалось на $\mathrm{BУC}$, приготовленных из шихты с соотношением КУ:БУ 70:30. Установлено, что эффективная вязкость снижалась с увеличением содержания пластификатора от 0,5 до 1,4 \% для всех исследованных содержаний угля в ВУС, а наиболее оптимальная концентрация пластификатора была в пределах $1 \%$.

Проведенные исследования по приготовлению ВУС в режиме одностадийного измельчения шихты с разным соотношением КУ:БУ и последующей гомогенизацией показали, что наиболее удовлетворительные характеристики по вязкости и стабильности были получены при содержании бурого угля 5-20\% и расходе пластификатора 1 \%. При этом содержание твердой фазы в полученных ВУС составляло 54-57 \% при содержании тонкой фракции (меньше 50 мкм) в пределах 60-65\%.

В случае получения водоугольного топлива из угольных шламов обогатительных фабрик в качестве твердой фазы в процессе получения ВУС использовались тонкодисперсные отходы углеобогащения - фильтр-кек и шламы обогатительных фабрик шахты «Заречная» и ОАО «Междуречье». В табл. 5 представлены характеристики шламов.

Зола имела следующий состав: $\mathrm{SiO}_{2}-49,5 \%, \mathrm{Al}_{2} \mathrm{O}_{3}-16,7 \%, \mathrm{Fe}_{2} \mathrm{O}_{3}-12,8 \%, \mathrm{CaO}-7,3 \%$, $\mathrm{MgO}-1,9 \%, \mathrm{TiO}_{2}-0,6 \%, \mathrm{MnO}_{2}-4,0 \%, \mathrm{SO}_{3}-0 \%, \mathrm{Na}_{2} \mathrm{O}+\mathrm{K}_{2} \mathrm{O}-0 \%, \mathrm{P}_{2} \mathrm{O}_{5}-0,12 \%$. Сущность процессов подготовки угольных шламов к использованию в виде ВУС заключалась в их 


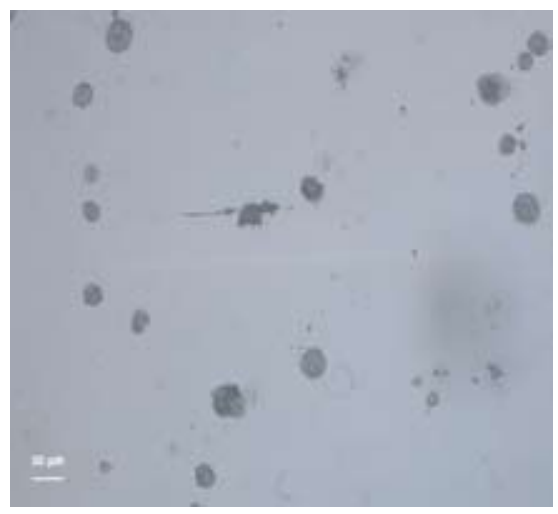

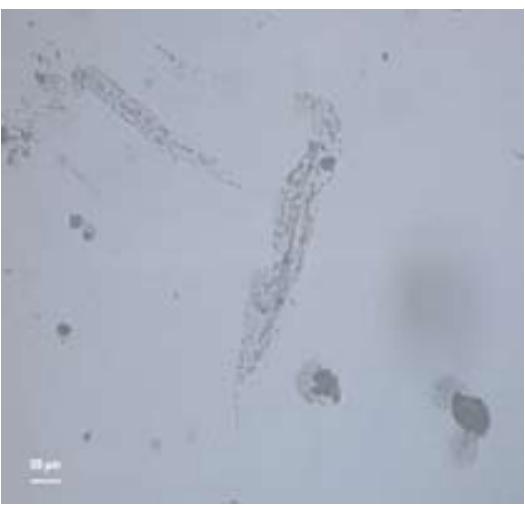

b

Рис. 2. Укрупненная капля ВУТ: $a$ - проба 1 (ОФ ОАО «Междуречье); $b$ - проба 2 (ОФШ «Заречная»)

Fig. 2. Enlarged drop of WCS: a - sample 1 (EF OJSC «Mezhdurechye»); b - sample 2 (EFS «Zarechnaya»)

сгущении тем или иным методом до максимально возможных значений, которые обусловлены технико-экономическими возможностями.

Микроскопирование проб ВУС на основе угольных шламов с использованием исследовательского микроскопа отраженного света Axio Observer.Z1m фирмы Carl Zeiss подтвердило предположение о возникновении наноразмерных структур в ходе механохимической деструкции угля в мельничных устройствах (рис. 2).

Для снижения вязкопластических характеристик ВУС на основе шламов были использованы комплексные химические добавки двух составов:

- ВМС+ЩР (щелочной реагент);

- ЛСТ + Щ.

Добавки вводились из расчета от 0,3 до 2 \% на сухую массу угля. Проведенные эксперименты выявили, что наибольший разжижающий эффект показала комплексная добавка 1. В этом случае получены ВУС с содержанием твердой фазы 55-56 \% и вязкостью эффективной 249 Па.с. Количество вводимой добавки составило 0,3 \% на сухую массу угля. В случае применения в качестве пластификатора ЛСТ $+\mathrm{NaOH}$ в количестве от 1 до $2 \%$ значения вязкости равнялись 474 Пасс и 100 Па·с соответственно. Но отрицательным моментом в этом случае является снижение стабильности ВУС. Так, проба ВУС с содержанием твердой фазы 61 \%, вязкостью 474 Па·с и количеством пластифицирующей добавки 1 \% расслоилась с образованием водной фазы в верхней части сосуда через 20 дней. Все остальные пробы показали хорошую стабильность в статических условиях (более 6 месяцев). При транспортировке проб ВУС автомобильным транспортом на расстояние 750 км расслоения не произошло, что говорит о высокой стабильности проб и в динамических условиях.

\section{Заключение}

Таким образом, проведенные экспериментальные исследования по изучению стабильности и реологических свойств водоугольных суспензий из бурых углей с зольностью от 10,6 до 31 \% показали следующее:

$$
-991-
$$


- суспензии, полученные из углей средней и высокой зольности (20-30 \%) без добавок и с применением гидроксида натрия, имели удовлетворительную статическую и динамическую стабильность;

- ВУС из малозольных углей ( $A^{d}$ - до $\left.11 \%\right)$ имели стабильность при хранении менее 30 сут, как без добавок, так и в присутствии пластификатора.

Также установлено, что из угольных шламов можно получить водоугольное топливо с высокими показателями стабильности и реологическими характеристиками. Выявлены некоторые закономерности процессов подготовки угольных шламов для технологии их промышленного использования. Исследованы стабилизационные и реологические характеристики ВУС, полученных с применением поверхностно-активных веществ.

Обнаруженные закономерности демонстрируют возможность оптимизации свойств суспензий в промышленных условиях совместным изменением количества добавки и регулированием физико-химического состава угля.

Исследование выполнено при финансовой поддержке Российского фонда фундаментальных исследований, Правительства Красноярского края, Красноярского краевого фонда поддержки научной и научно-технической деятельности» в рамках научного проекта № 17-48-240386 p_a.

\section{Список литературы}

[1] Zasypkin I., Murko V., Fedyaev V., Baranova M. Systems of ignition and combustion stabilization for water-coal fuel, J. Thermal Science. 2012. Vol. 16. No. 4. 1329-1338.

[2] The Usage Of Boilers With A Furnace For Burning Enrichment Products And Deballasting Coal. Murko V.I., Puzyryov E.M., Karpenok V.I. etc. XVIII Internation Coal Preparation Congress, Saint-Petersburg, Russia, 2016. 345-350.

[3] Баранова М.П. Комплексная технология получения и транспорта водоугольных топливных суспензий из углей разной степени метаморфизма. Журн. Сиб. фед. ун-та. 2011, 4(6), $613-$ 619. [Baranova M.P. Complex technology of obtaining and transporting water-coal fuel suspensions from coals of different degrees of metamorphism, Journal of Siberian Federal University. Engineering \& Technologies, 2011, 4(6), 613-619 (in Russian)].

[4] Baranova M.P., Kulagin V.A., Taraban'ko V.E. Nature of stabilization of water-coal fuel suspensions. Russian Journal of Applied Chemistry, June 2011, Vol. 84, Issue 6, 939-944.

[5] Баранова М.П., Екатеринчев В.М. Возможность использования вторичных ресурсов в технологии получеsния топливных водоугольных суспензий, Ползуновский вестник. 2011. № 2/1. 235-238 [Baranova M.P., Yekaterinov V.M. The possibility of using secondary resources in the technology of obtaining fuel water-coal suspensions, Polzunovsky Herald. 2011. № 2/1. 235-238 (in Russian)]. 